\title{
Article \\ Research on Cascaded Single Phase PFC Based on Predictive PI Control
}

\author{
Guoping Shi and Yece Qian *(D) \\ College of Mechanical and Electrical Engineering, Chizhou University, Chizhou 247000, China; \\ sgpapple@czu.edu.cn \\ * Correspondence: 0120110561@czu.edu.cn
}

check for

updates

Citation: Shi, G.; Qian, Y. Research on Cascaded Single Phase PFC Based on Predictive PI Control. World Electr. Veh. J. 2022, 13, 48. https://doi.org/ 10.3390/wevj13030048

Academic Editor: Joeri Van Mierlo

Received: 22 January 2022

Accepted: 25 February 2022

Published: 2 March 2022

Publisher's Note: MDPI stays neutral with regard to jurisdictional claims in published maps and institutional affiliations.

Copyright: (c) 2022 by the authors. Licensee MDPI, Basel, Switzerland. This article is an open access article distributed under the terms and conditions of the Creative Commons Attribution (CC BY) license (https:// creativecommons.org/licenses/by/ $4.0 /)$.

\begin{abstract}
In order to improve the charging speed and reduce the occupied volume of an electric vehicle charger, a single-phase boost power factor corrector (PFC) system with cascade CHB (cascaded H-bridge) topology was adopted. Due to the periodic fluctuation of single-phase AC input, there is a large double power frequency ripple component in the output voltage of an AC-DC converter. When capacitor voltage is used as output for feedback control, the control system has the characteristics of a non-minimum phase system. In light of these factors that affect the dynamic stability of the system, a control method is proposed to improve the dynamic characteristics of the system without affecting its steady-state performance. The predictive PI control strategy was adopted to predict the error input signal of the lag process to attenuate the jitter in the control system and improve the dynamic performance and anti-interference of the system. Finally, the feasibility of the scheme was verified by experiments.
\end{abstract}

Keywords: power factor corrector; AC-DC converter; dynamic stability; predictive PI control

\section{Introduction}

With the rapid development of the electric vehicle industry, the charging speed and convenience of electric vehicles have been put forward as having higher requirements. Electric vehicle charging can be divided into DC charging and AC charging. DC charging charges the battery by the public fast charging pile, which is fast but inconvenient; AC charging charges the vehicle power battery indirectly, when the AC current is converted by the on-board charger. It can be charged in private places and is more popular with ordinary consumers [1]. Generally, the three-phase circuit is used in high-power occasions (such as charging pile, etc.). In daily life, the most common power distribution mode is single-phase electricity, so the power supply mode of a vehicle charger mostly adopts single-phase AC power supply. The main circuit converter designed in this project adopted the single-phase AC-DC structure. However, the charging speed is limited due to the small charging power. If the charging power of on-board charger is increased, it will be restricted by the space of the electric vehicle itself. The inductor volume accounts for about $36 \%$ of the total PFC volume [2]. The inductor volume depends on the inductor volume and peak current, and the inductor volume is determined by its volt-second [3]. The inductance can be reduced by increasing the switching frequency of the system and reducing the voltage at both ends of the inductor to reduce the volume of the inductor. The cascaded H-bridge converter increases the number of levels to reduce the voltage at both ends of the inductor, and the carrier phase-shift modulation can greatly increase the frequency of the inductor current $[4,5]$. With the increase in the number of levels, the inductance volume gradually decreases. When it increases from three levels to eleven levels, the inductance volume can be reduced by about 90\% [6]. Therefore, the single-phase AC-DC converter designed in this project adopted cascade structure and carrier phase shift modulation.

Due to the periodic pulsation of single-phase AC input, the output voltage of the AC-DC converter will inevitably have a large double power frequency ripple component. 
The second harmonic component of the output voltage is fed back to the outer voltage loop, resulting in the distortion of the reference current generated by the output signal of the compensator, and the third harmonic current will be generated in the AC side. Therefore, the bandwidth of the voltage loop is usually limited to a frequency much lower than the ripple frequency to avoid the input current waveform distortion caused by the fast response speed of the voltage loop and the fast change of the turn-on time. For the application where the load is basically stable, the lower voltage loop bandwidth can meet the system requirements. However, in the application where the load is often changing rapidly, the circuit response speed is slow, and the interference will lead to the voltage fluctuation of the output DC bus, which will cause additional pressure on the devices in the system. This not only reduces the control performance of the system, but also does harm to the load $[7,8]$. In addition, the voltage power level transfer function of the AC-DC converter is the transfer function of non-minimum phase system, so it is necessary to suppress the negative regulation caused by unstable zero and shorten the regulation time of the system [9]. Therefore, it is of great significance to reduce the overshoot and adjustment time and improve the dynamic response ability of the system.

In order to ensure high-quality input current waveform control and effectively improve the dynamic performance of a single-phase AC-DC converter, some scholars have eliminated the ripple component of DC output voltage from the hardware level of the main circuit. A passive scheme is adopted, in which the LC resonant branch is paralleled on the DC output bus of a single-phase AC-DC converter to bypass the second harmonic current at the output [10]. The main circuit is embedded with a branch especially used to buffer the instantaneous power difference to balance the instantaneous power between the input and output [11]. An active energy storage unit is paralleled on the DC output bus to filter the second harmonic current at the output [12]. The methods described above all increase passive components, while inductance or capacitance will make the circuit order higher and robustness lower, which makes the analysis more complicated.

Some scholars have used the load dynamic information feedforward method to improve the system dynamic response speed. Effective feedforward schemes include load current feedforward, DC output voltage ripple feedforward and load power feedforward, etc. In [13], the load current feedforward is introduced to counteract the influence of load disturbance on the control system. On the basis of average current control, an improved double feedforward control including input and load feedforward was proposed in [14] to optimize the dynamic response of the system, and the peak voltage prediction was used to further improve the performance of the control. A real-time load prediction voltage loop output was proposed, and then the duty cycle was calculated directly from the voltage loop output in [15]. An adaptive constant power control method, adaptive constant power angle operation, has been proposed to achieve efficiency control under light load, while still meeting the output voltage requirements [16]. A comprehensive sliding mode control method was proposed to improve the dynamic performance of the converter and ensure the unity power factor by selecting the appropriate sliding surface coefficient [17]. A feed-forward method was proposed to compensate the harmonic distortion of the reference current by introducing the harmonic component of the input current into the control loop [18]. However, the above scheme requires additional sensors or observers to detect the load current or power feedforward signals, which increases the complexity and cost of the system.

In this paper, a cascaded multilevel PFC scheme was proposed, which will effectively improve the power density of the system. The flying capacitor multilevel circuit with carrier phase-shifting modulation not only increases the frequency of the inductor current, but also decreases the maximum voltage at both ends of the inductor. The predictive PI control algorithm was proposed to improve the dynamic performance of the single-phase cascade PFC system. Facing the problem of a non-minimum phase system in voltage loop, the predictive PI control strategy was used to predict the error input signal of the delay process to attenuate the jitter in the control system and improve the dynamic performance and anti-interference of the system. 
The rest of this paper is organized as follows. Section 1 reports the existing works of cascaded single phase PFC. Section 2 introduces the structure of a cascaded single phase PFC system. Section 3 details the design of cascade single phase PFC control system. Section 4 details the system experimental analysis. Finally, Section 5 presents the conclusions of this paper.

\section{Structure of Cascaded Single Phase PFC System}

Figure 1 shows the topology of a single-phase $\mathrm{N}$-unit cascaded $\mathrm{PFC}$, which is composed of $\mathrm{N} \mathrm{H}$-bridge units in series. On the AC side, vs. is the grid voltage, $i_{\mathrm{s}}$ is the AC side current, $L_{\mathrm{S}}$ is the filter inductor, $C_{\mathrm{S}}$ is the filter capacitor, $L$ is the boost inductor, and $i_{\mathrm{L}}$ is the current flowing through the inductor $L . C_{i}$ and $R_{i}(i=1,2 \ldots N)$ are the capacitors and DC loads. On the DC side, $v_{\mathrm{dc} 1}, v_{\mathrm{dc} 2} \ldots v_{\mathrm{dcN}}$ are the voltages across the capacitors' side of the $\mathrm{H}$-bridge. The DC load $R_{i}$ is used to replace the PFC post stage converter, where $i$ is the serial connection unit number.

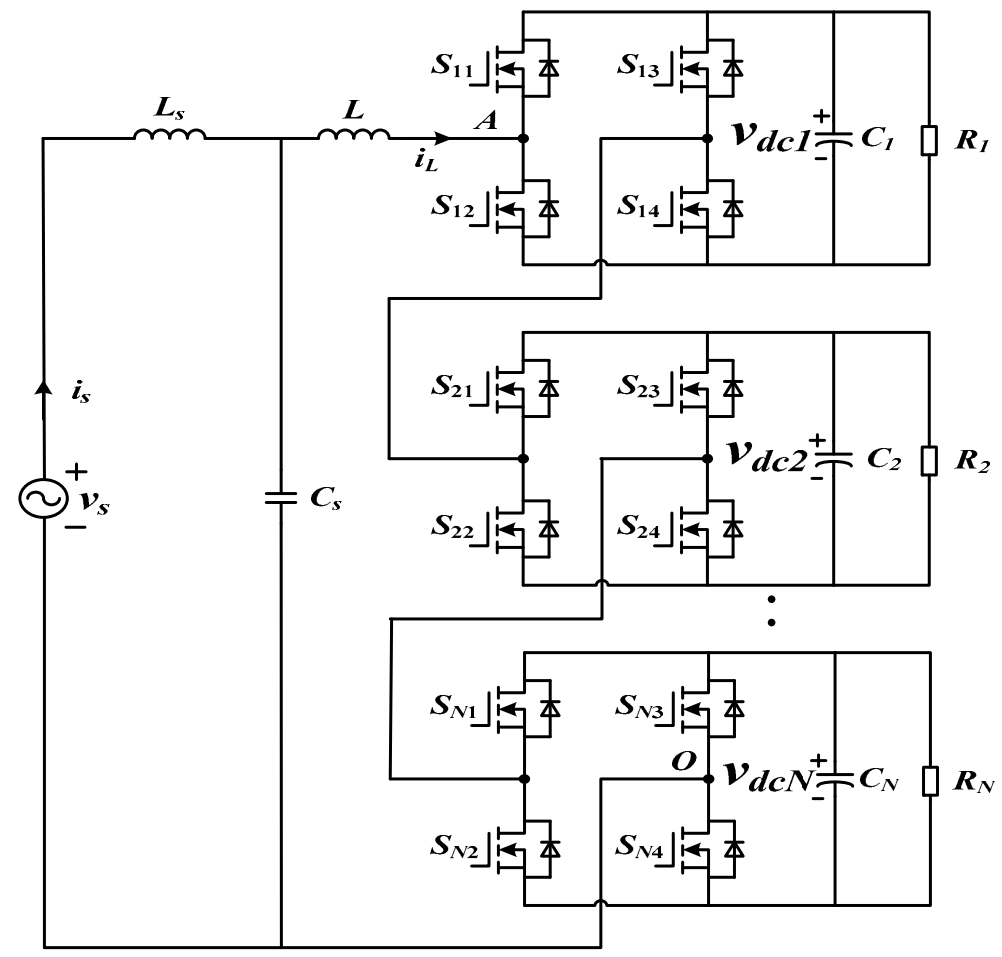

Figure 1. Topology of a single-phase $N$-cell CHB PFC.

For the convenience of analysis, the following assumptions can be made:

(1) The common duty cycle control strategy is adopted, and the difference of switching function caused by CPS-SPWM is ignored, that is, $m_{1} \approx m_{2} \approx \ldots \approx m_{i}$; and

(2) The capacitance and resistance of the DC side are the same, which are $C$ and $R$, respectively.

The modulation waveforms of unit $i$ and unit $i+1$ are shown in Figure 2. For the CHB of $N$ units, the carrier phase difference between the left and right bridge arms of each unit is $180^{\circ}$, and the carrier phase difference between the bridge arms of adjacent units is $180^{\circ} / \mathrm{n}$, 


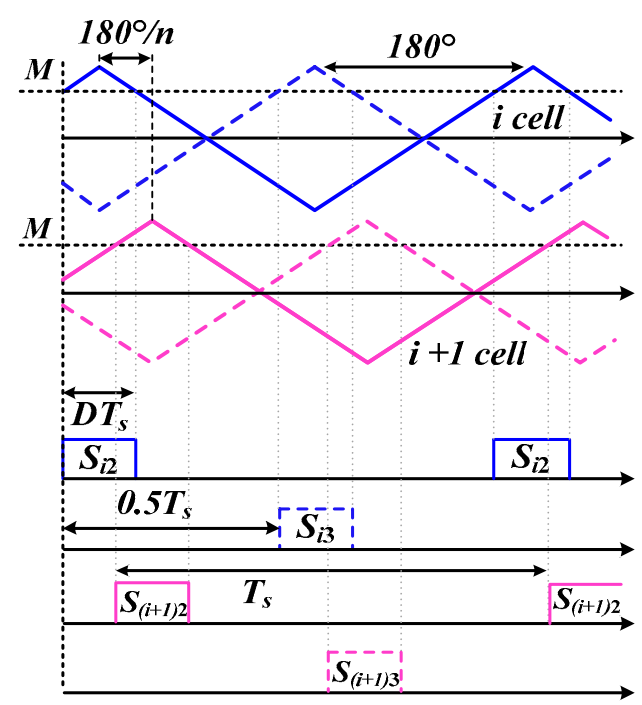

Figure 2. Modulation waveforms of unit $i$ and unit $i+1$.

By using Kirchhoff's law of voltage and current, the following relation can be obtained as Equation (1):

$$
\left\{\begin{array}{l}
L \frac{d i_{L}}{d t}=v_{S}-\sum_{i=1}^{N} m v_{d c i}(i=1 \cdots N) \\
C \frac{d v_{d c i}}{d t}=m i_{L}-\frac{v_{d c i}}{R}(i=1 \cdots N)
\end{array}\right.
$$

where $m=v_{s} / N v_{d c}, v_{d c}=v_{d c 1}=v_{d c 2} \cdots=v_{d c N}$.

On the basis of this large signal, small signal disturbance was added, as shown in Equation (2).

$$
\left\{\begin{array}{l}
v_{i n}=V_{i n}+\hat{v}_{i n} \\
i_{i n}=I_{i n}+\hat{i}_{i n} \\
v_{d c j}=V_{d c j}+\hat{v}_{d c j} \\
M=M+\hat{m}
\end{array}\right.
$$

The disturbance is substituted into the large signal and Laplace transform is performed as Equation (3):

$$
\left\{\begin{array}{c}
s L \hat{v}_{i n} \hat{i}_{L}(s)=\hat{v}_{s}(s)-N V_{d c} \hat{m}(s)-M \sum_{i=1}^{N} V_{d c i}(s) \\
s C V_{d c i}(s)=I_{L} \hat{m}(s)+M \hat{i}_{L}(s)-\frac{1}{R} V_{d c i}(s)(i=1 \cdots N)
\end{array}\right.
$$

By eliminating the DC component and ignoring the second-order small signal component, the small signal power stage transfer function of a single-phase cascaded PFC converter can be obtained.

The transfer function of grid current relative to duty cycle is as follows:

$$
G_{i m}(s)=\frac{-N R C V_{d c} s+2 N V_{d c}}{R L C s^{2}+L s+M^{3} N R}
$$

The transfer function of bus voltage relative to duty cycle is as follows:

$$
G_{v m}(s)=\frac{-L V_{d c} s+M^{2} N R V_{d c}}{M R L C s^{2}+M L s+M^{3} N R}
$$

It can be seen from (5) that the transfer function is the transfer function of a nonminimum phase system, and its open-loop step curve has negative modulation at the beginning. The system has a zero point in the right half plane, which will deteriorate the 
dynamic quality of the control system and lead to a longer transition time of the system. Moreover, in the negative regulation period, the controller receives the opposite feedback signal, forming a positive feedback system and affecting the steady-state performance of the system.

\section{Design of Cascade Single Phase PFC Control System}

The second harmonic component exists in the output voltage of the AC-DC converter in a single-phase cascaded PFC system, which limits the bandwidth frequency of voltage loop. The voltage power level transfer function of the AC-DC converter is the transfer function of a non-minimum phase system, which affects the dynamic stability of the system. Aiming at the nonlinear characteristics of the above single-phase cascaded PFC system, this paper adopts the double loop control of the voltage outer loop and current inner loop. In the voltage outer loop, predictive PI control was used to improve the dynamic performance of the system. The inner current loop adopts the proportional integral control with simple structure, which not only does not affect the control effect, but also simplifies the control method $[19,20]$. The schematic diagram of predictive PI control is shown in Figure 3.

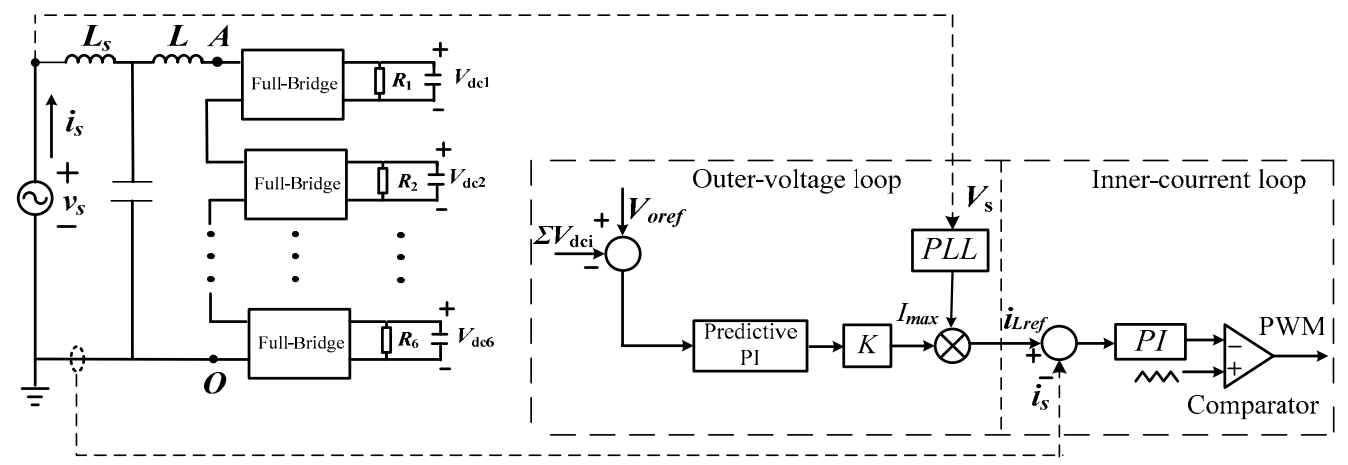

Figure 3. Control schematic diagram of the PFC system.

According to Figure 3, in the external voltage loop of a single-phase cascade PFC circuit control system, the voltage sampling value $\Sigma V_{\mathrm{dci}}$ is the sum of $N$ capacitor voltages. First, the given value of the voltage loop is compared with the average value of the capacitor voltage obtained by sampling, and the voltage error value is used as the input of the secondorder notch filter. The secondary voltage ripple is filtered to improve the bandwidth of the voltage loop. The filtered signal is controlled by predictive PI to eliminate the negative modulation and improve the dynamic performance and anti-interference ability of the system. The maximum value of the current reference value of the appreciating inductor is obtained by multiplying the output signal of the predictive PI control by the scale factor. Then, the maximum value is multiplied by the sinusoidal value of the phase information of the power grid voltage processed by the phase locked loop, and the result is taken as the given value of the current loop. The current error is obtained by comparing the collected boost inductor current with the current reference value. The current error is adjusted by the PI controller, and then compared with triangular wave to obtain the control value. The obtained control quantity is input into the DPWM module to generate pulse, which can control the power switch after passing through the driving circuit [21,22].

\subsection{Predictive PI Control}

Since 1992, the idea of predictive PI controller was put forward by Hagland. After step-by-step research and practice, predictive PI control algorithm was successfully applied to complex control systems, especially in the predictive control of multivariable models. This control strategy has a good effect in dealing with feedback mutation and conditional constraints.

The predictive PI control algorithm combines the predictive strategy with the traditional PI control method, and introduces the relevant closed-loop transfer function into 
the traditional PI control algorithm, so that the whole control strategy not only has the advantages of easy realization of the PI controller, but also has a predictive function. In the face of the first-order inertia lag model, the predictive PI control algorithm can improve the delay of the controlled object and optimize the whole control process effectively. Moreover, the predictive PI controller has excellent robustness and stability. When the actual model parameters of the controlled object change in a certain range, it can also ensure the good performance of the negative feedback system $[23,24]$. The schematic diagram of predictive PI control is shown in Figure 4.

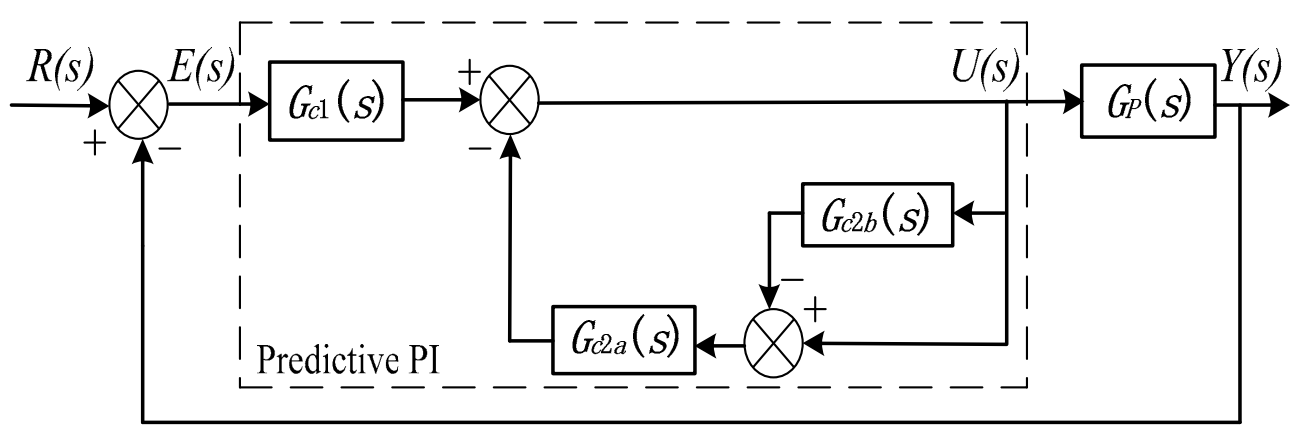

Figure 4. Schematic diagram of predictive PI control.

In Figure 4, $E(s)$ and $U(s)$ are divided into input variables and output variables of the predictive PI controller. The transfer function $G_{c}(s)$ of the predictive PI controller is composed of $G_{c 1}(s)$ and $G_{c 2}(s)$. Among them, $G_{c 1}(s)$ plays a traditional PI control function, $G_{c 2}(s)$ plays a predictive role, and $G_{c 2}(s)$ is composed of $G_{c 2 a}(s)$ and $G_{c 2 b}(s)$. $G_{P}(s)$ is the transfer function of the controlled object.

The closed-loop transfer function of the unit negative feedback system is as follows:

$$
G(s)=\frac{G_{C}(s) G_{P}(s)}{1+G_{C}(s) G_{P}(s)}
$$

Then, the transfer function of the controller is as in Equation (7):

$$
G_{C}(s)=\frac{G(s)}{G_{P}(s)(1-G(s))}
$$

It is assumed that the mathematical model of the process system object is as follows:

$$
G_{P}(s)=\frac{K}{T s+1} e^{-\tau s}
$$

The expected closed-loop transfer function is as follows:

$$
G(s)=\frac{1}{\lambda T s+1} e^{-\tau s}
$$

The predictive PI control algorithm introduces adjustable variable parameters, which can change the real-time response speed of the control system. When $\lambda=1$, the openloop response time constant of the control system is consistent with the negative feedback closed-loop response time constant. When $\lambda<1$, the response time constant of the negative feedback closed-loop is smaller; when $\lambda>1$, the response time constant of the negative feedback closed-loop is larger.

Substituting Equations (8) and (9) into Equation (7), the transfer function of the controller can be obtained as follows:

$$
G_{C}(s)=\frac{U(s)}{E(s)}=\frac{G(s)}{G_{P}(s)(1-G(s))}=\frac{1+T s}{K\left(1+\lambda T s-e^{-\tau s}\right)}
$$


Equation (10) is transformed into:

$$
U(s)=G_{c 1}(s) E(s)-G_{c 2}(s) U(s)=\frac{1}{\lambda k_{p}}\left(1+\frac{1}{T s}\right) E(s)-\frac{1}{\lambda T s}\left(1-e^{-\tau s}\right) U(s)
$$

From Equation (11), Equations (12) and (13) can be obtained:

$$
\begin{gathered}
G_{c 1}(s)=\frac{1}{\lambda k_{p}}\left(1+\frac{1}{T s}\right) \\
G_{c 2}(s)=G_{c 2 a}(s)\left(1-G_{c 2 b}(s)\right)=\frac{1}{\lambda T s}\left(1-e^{-\tau s}\right)
\end{gathered}
$$

$G_{c 1}(s)$ is a traditional PI controller, which is the main control part of the predictive PI control strategy. In a certain range, $G_{c 1}(s)$ reacts to the internal and external disturbances and real-time parameter changes of the system to ensure the robustness of the whole control strategy. $G_{c 2}(s)$ is the predictive part of the predictive PI control strategy, which means that the controller outputs the predictive value at a certain time in $[t-\tau, t]$, so that the controller and the controlled object can be combined to determine the current optimal value by rolling optimization, and the bad influence of the pure delay link on the control system can also be reduced.

It can be seen from Equation (11) that the predictive PI control algorithm contains multiple variable parameters, where $K$ is the gain in the control process, $\tau$ is the delay time variable parameter of the control process, $T$ is the time constant of the transition process, and $\lambda$ is the parameter of the regulating variable. Therefore, the parameters of $K, T$, and $\tau$ need to be determined. The following is the process of determining the parameters of the three variables.

The first order Pade approximation of Equation (5) is carried out:

$$
e^{-\tau s}=\frac{1-0.5 \tau s}{1+0.5 \tau s}
$$

The first-order Pade approximation of Equation (5) is used to synthesize a delay system to eliminate the negative modulation, as shown in Equation (15).

$$
\begin{gathered}
G_{v m}(s)=\frac{L U_{d c} s+M^{2} N R V_{d c}}{M R L C s^{2}+M L s+M^{3} N R} e^{-2 T_{P} s} \\
T_{P}=\frac{L}{M^{2} N R}
\end{gathered}
$$

It can be seen from Equation (15) that the system becomes a non-minimum phase system with a delay link, which is a special case of non-minimum phase system with zero of the right half complex plane. $T_{P}$ in Equation (16) is the delay time variable parameter of the control process. It is necessary to further identify and fit the system using the identification of the second-order under-damped self regulating plant. For the transfer function (17):

$$
G(s)=\frac{K \omega^{2}}{s^{2}+2 \xi \omega s+\omega^{2}}
$$

where $\omega$ is the natural angular frequency, $\xi$ is the damping coefficient.

Under the step input excitation, the output of the system will vibrate. Equation (18) is the dimensionless curve that obtained by the Laplace transform of the transfer function.

$$
Y(s)=1-\frac{e^{-\tilde{\xi} \omega s}}{\sqrt{1-\xi^{2}}} \sin \left(\sqrt{1-\xi^{2}} \omega s+\varphi\right)
$$


where $\xi, \varphi$, and $\omega$ can be expressed as follows:

$$
\begin{gathered}
\xi=\frac{1}{\sqrt{1+\left(\pi / \ln Y_{1}\right)}} \\
\operatorname{tg} \varphi=\frac{\sqrt{1-\xi^{2}}}{\xi} \\
\omega=\frac{2 \pi}{T \sqrt{1-\xi^{2}}}
\end{gathered}
$$

According to Equations (18)-(21), the fitted transfer function $G(s)$ can be obtained, and the curve $y(t)$ is obtained by step response of the transfer function $G(s)$.

\subsubsection{The Determination of Parameter K}

Through the step response curve, the steady-state value $y(\infty)$ of the controlled variable is estimated, and the static amplification factor or steady-state gain $K$ is calculated as:

$$
K=\frac{y(\infty)-y(0)}{r}
$$

where $y(\infty)$ and $y(0)$ are the final steady-state value and the original steady-state value of the output, respectively, and $\mathrm{R}$ is the change in the step input.

\subsubsection{Determination of Parameters $T$ and $\tau$}

Continue to use the calculation method to fit the transfer function $G(s)$ of the firstorder inertial object. The following is to identify the required transfer function by the calculation method.

Dimensionless step response curve $y^{*}(t)$ can be expressed as Equation (23). Measure the values of $y^{*}\left(t_{1}\right)$ and $y^{*}\left(t_{2}\right)$ corresponding to $t_{1}$ and $t_{2}$ on the response curve of the transfer function $G(s)$, and then calculate the value of $T$ and $\tau$ according to Equations (24) and (25).

$$
\begin{gathered}
y^{*}(t)=\frac{y(t)}{y(\infty)} \\
T=\frac{t_{2}-t_{1}}{\ln \left[1-y^{*}\left(t_{1}\right)\right]-\ln \left[1-y^{*}\left(t_{2}\right)\right]} \\
\tau=\frac{t_{2} \ln \left[1-y^{*}\left(t_{1}\right)\right]-t_{1} \ln \left[1-y^{*}\left(t_{2}\right)\right]}{\ln \left[1-y^{*}\left(t_{1}\right)\right]-\ln \left[1-y^{*}\left(t_{2}\right)\right]}
\end{gathered}
$$

Because the output voltage of the system has a power frequency ripple with large amplitude, the bandwidth of the voltage loop is usually limited to avoid the distortion of the input current waveform caused by the too fast response speed of the voltage loop and the too fast change of the opening time. Figure 5a is the open-loop Bode diagram of the outer voltage loop before compensation, and Figure $5 b$ is the open-loop Bode diagram of the outer voltage loop after compensation. The phase margin was about $60^{\circ}$, which meets the requirement of system stability. The crossing frequency was $300 \mathrm{~Hz}$, which is consistent with the design value.

Figure 6 shows the error and absolute error between the actual value and predicted value of the PI control, where $x_{0}$ is the actual output value of PI, $x_{1}$ is the predicted value of $\mathrm{PI}, e$ is the absolute error between the predicted value $x_{1}$ and the actual value $x_{0}$, and $e_{\mathrm{ss}}$ is the relative error between the predicted value $x_{1}$ and the actual value $x_{0}$. It can be seen that the predicted value $x_{1}$ tracked the actual value $x_{0}$ well. In steady state, the absolute error and relative error are very small. At $0.25 \mathrm{~s}$, the system load changes, the absolute error and relative error fluctuate, but after $0.04 \mathrm{~s}$ adjustment, it is stable. 


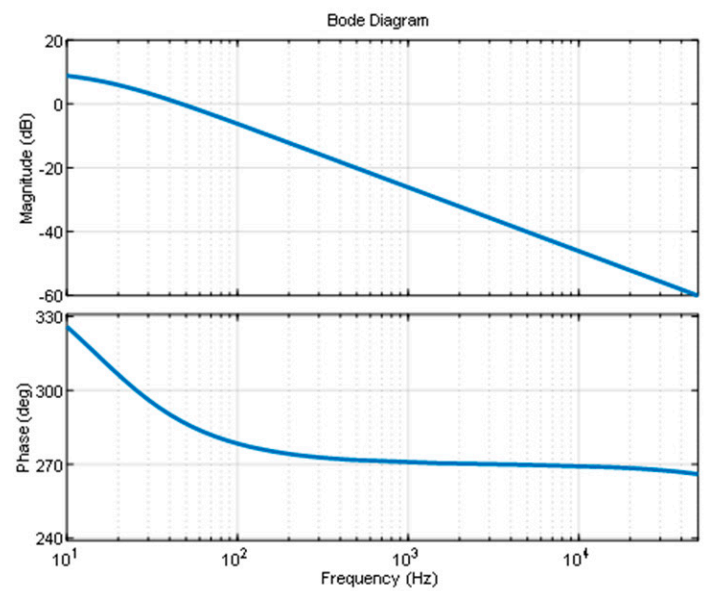

(a)

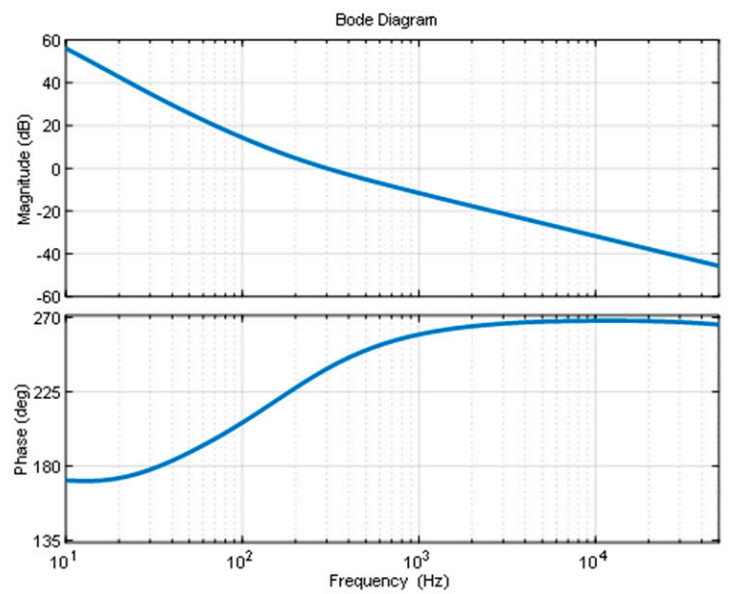

(b)

Figure 5. The open-loop Bode diagram of the outer voltage loop: (a) Open loop Bode diagram of voltage loop before compensation and (b) open loop Bode diagram of compensated voltage loop.

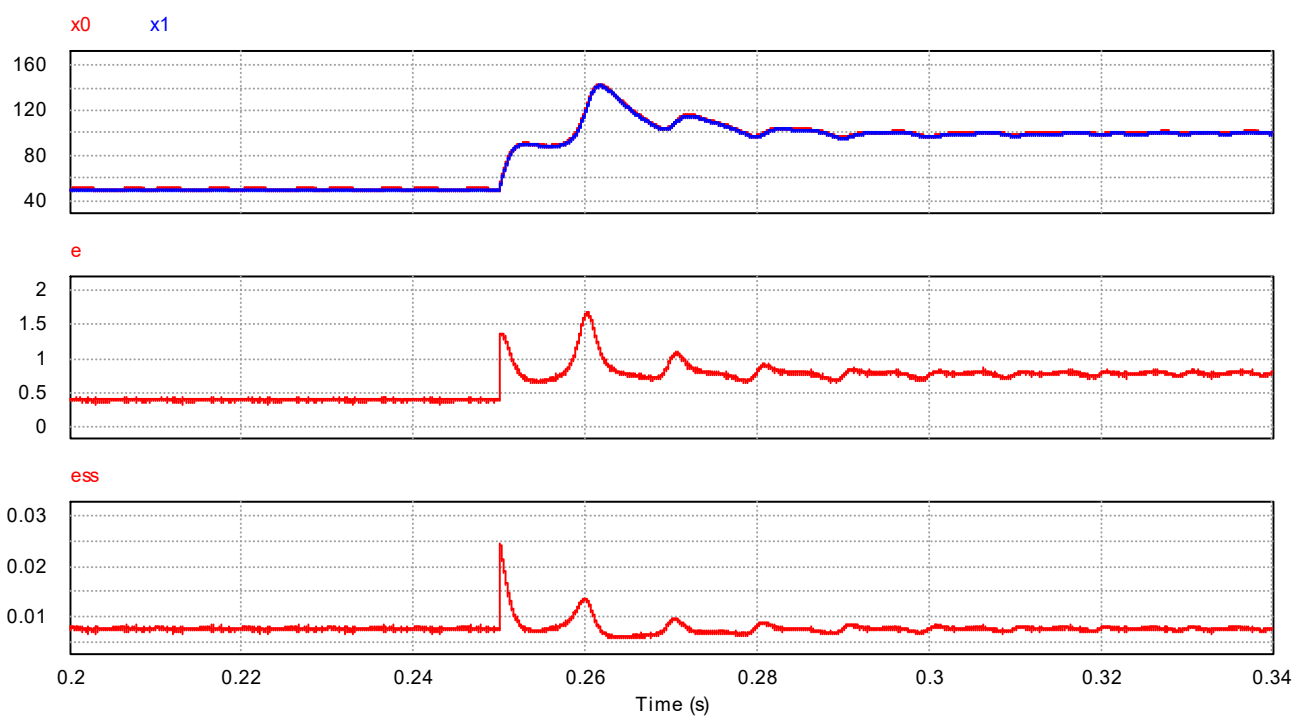

Figure 6. Error and absolute error between the actual value and predicted value of PI control.

\subsection{Current Inner Loop Control}

The control block diagram of the current inner loop is shown in Figure 7. $G_{i m}(s)$ is the transfer function of current power level, and $G_{c i}(s)$ is the PI control.

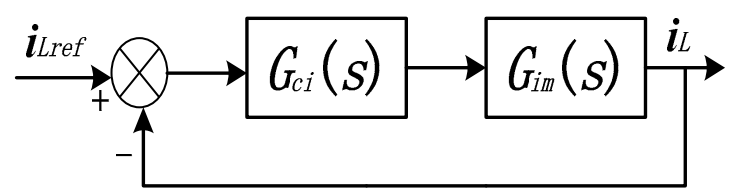

Figure 7. Control schematic diagram of the PFC system's current inner loop.

The transfer function of PI control can be expressed as Equation (26).

$$
G_{c i}(s)=K_{p i} \times \frac{1+T_{i c} \mathcal{S}}{T_{i c} \mathcal{S}}=K_{p i}+\frac{K_{i i}}{s}
$$

where $K_{p i}$ is the gain of current controller, which can be obtained by Equation (27). $K_{i i}$ is the current loop integration coefficient and $T_{i c}$ is the current loop integration time constant, 
which can be obtained by Equation (28). $f_{c}$ is the shear frequency, so the phase margin of the current loop near the shear frequency should be large enough. $f_{d}$ is the compensation zero of the current loop controller.

$$
\begin{gathered}
k_{p i}=\frac{2 \pi f_{c} L}{V_{o} k_{s i}} \\
T_{i c}=\frac{1}{2 \pi f_{d}}
\end{gathered}
$$

Since the switching frequency of the system is $60 \mathrm{kHZ}$, the crossing frequency of the current loop was set as $1 / 10$ of the switching frequency, which was $6 \mathrm{kHz}$. Figure $8 \mathrm{a}$ is the open-loop Bode diagram of the inner current loop before compensation, and Figure $8 \mathrm{~b}$ is the open-loop Bode diagram of the inner current loop after compensation. The phase margin was about $60^{\circ}$, which met the requirement of system stability. The crossing frequency was $6 \mathrm{kHz}$, which is consistent with the design value.

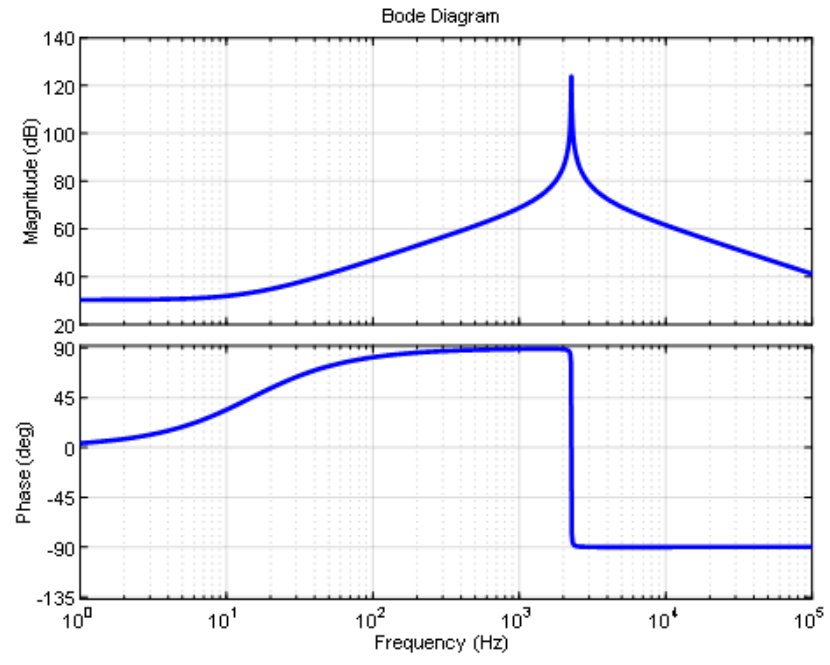

(a)

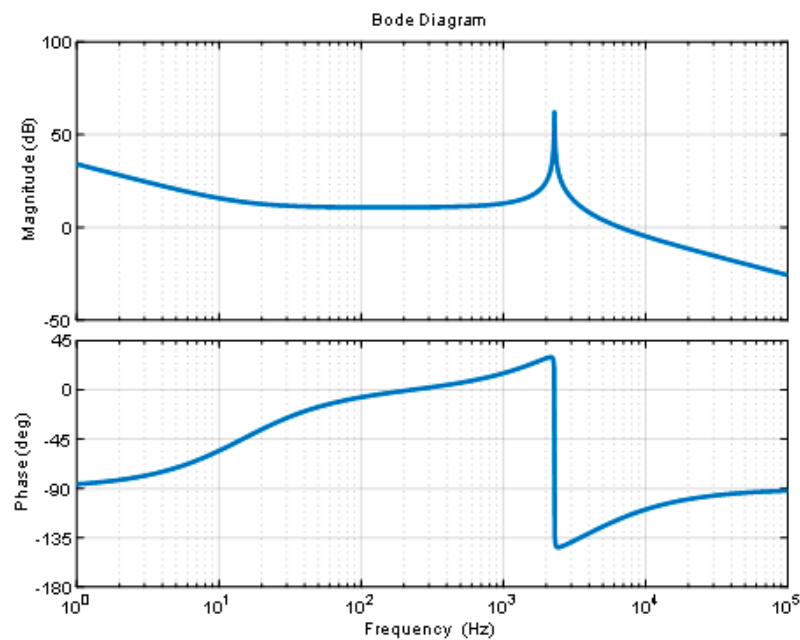

(b)

Figure 8. The open-loop Bode diagram of the inner current loop: (a) Open loop Bode diagram of current loop before compensation; (b) Open loop Bode diagram of compensated current loop.

\section{System Experimental Analysis}

The experiment adopted a PFC prototype with a rated power of $2 \mathrm{~kW}$, the main circuit adopted a CHB topology of six units, the switch adopted a $100 \mathrm{~V} 4 \mathrm{~m} \Omega$ gallium nitride device, and the control chip was composed of DSP and FPGA. The picture of the main circuit and control circuit of the experimental prototype is shown in Figure 9. Important components and models used in the prototype are shown in Table 1. Experimental parameters used in the prototype are shown in Table 2.

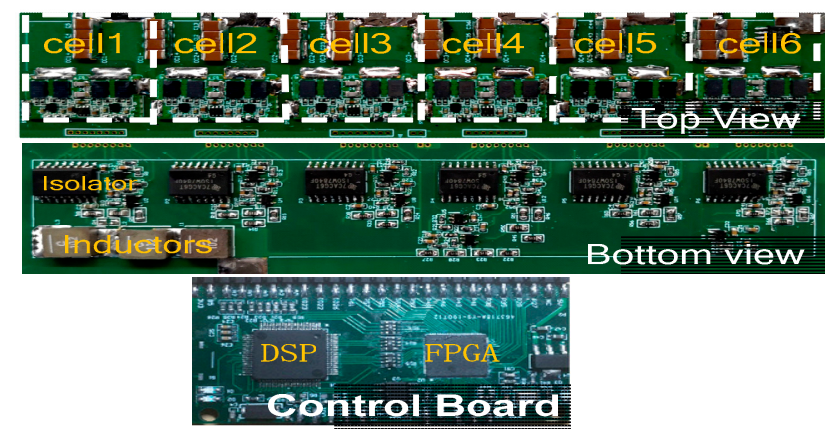

Figure 9. Photo of the main circuit and control circuit of the experimental prototype. 
Table 1. Important components and models used in the prototype.

\begin{tabular}{cc}
\hline Component & Model \\
\hline Switch tube & EPC2032 \\
Isolator & ISOW7840 \\
Driver & LMG1205 \\
Driver power supply & TPS60150 \\
Current sensor & ACS723 \\
DSP & TMS320F28069 \\
FPGA & AL3S10NG88 \\
\hline
\end{tabular}

Table 2. Experimental parameters used in the prototype.

\begin{tabular}{cc}
\hline Parameter & Values \\
\hline Main inductance & $5 \mu \mathrm{H}$ \\
Filter inductance & $8 \mu \mathrm{H}$ \\
Filter capacitor & $620 \mathrm{nF}$ \\
Unit bus capacitance & $1800 \mu \mathrm{F}$ \\
Unit resistive load & $12 \Omega$ \\
Switching frequency & $60 \mathrm{kHz}$ \\
AC side phase voltage & $220 \mathrm{~V}$ \\
DC side voltage & $360 \mathrm{~V}$ \\
Rated power & $2 \mathrm{~kW}$ \\
Power density & $1500 \mathrm{~W} / \mathrm{in}^{3}$ \\
\hline
\end{tabular}

\subsection{System Steady-State Experimental Analysis}

Figure 10 is the system steady-state experimental waveform where vs. is the power supply voltage at the AC side of the system; $V_{\mathrm{AO}}$ is the bus voltage at the AC side of the system; and $i_{\mathrm{S}}$ is the bus current at the AC side of the system and $i_{\mathrm{L}}$ is the current of boost inductor $L$. Figure 11 is the system switching cycle waveform. $T_{\mathrm{S}}$ is the normal switching cycle of each switch, and $T_{\mathrm{cs}}$ is the switching period of each switch after carrier phase-shifting modulation.

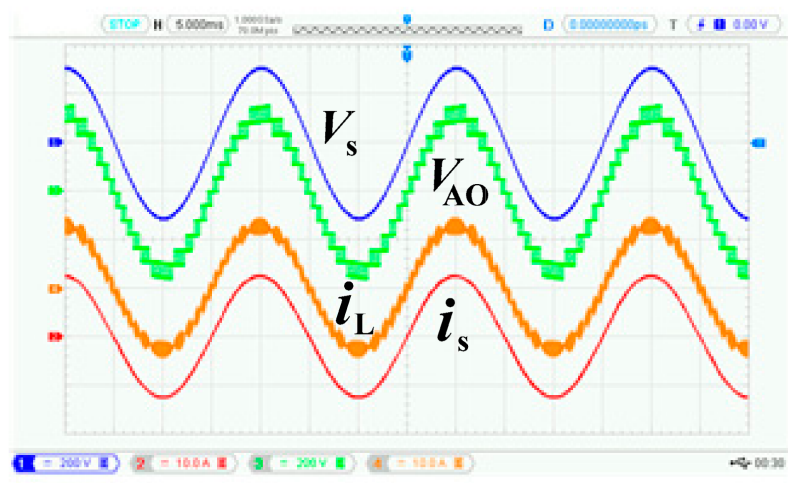

Figure 10. AC side experimental waveform of the steady-state system.

In order to minimize the volt second of the inductance, it is necessary to ensure that the difference between the voltage at two points of $\mathrm{AO}$ and the input voltage is not greater than one level voltage during modulation. With the increase in the number of levels, the inductance volume gradually decreases. It is obvious from Figure 10 that when the input voltage is $220 \mathrm{~V}$, all 13 level voltages will appear between $\mathrm{AO}$, so the voltage borne by each switch tube is greatly reduced. Under full load conditions, the phase difference between the grid current and voltage is very small, and PF can reach 0.99 . For the switching cycle, it can be clearly found from Figure 11 that the switching frequency of each switch tube is $60 \mathrm{kHZ}$. Through carrier phase-shifting control, the equivalent frequency is increased by 
12 times to $720 \mathrm{kHZ}$, which greatly reduces the burden of each switch tube and reduces the switching loss.

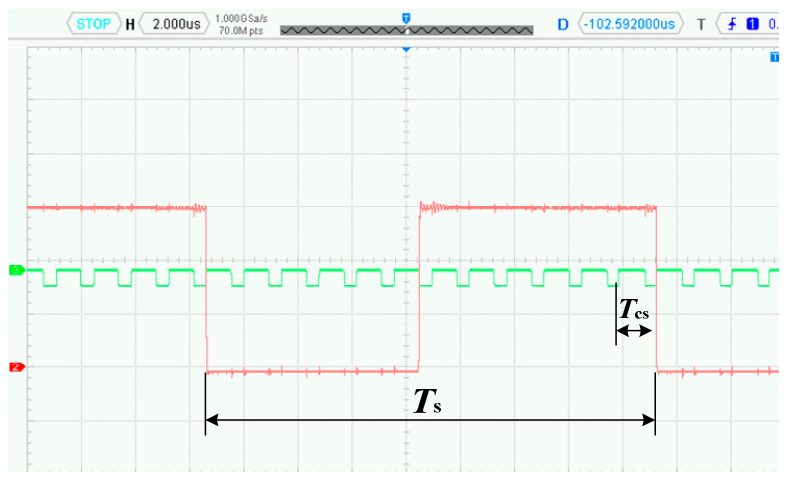

Figure 11. Switching cycle waveform.

\subsection{System Dynamic Experimental Analysis}

Figure 12 is the experimental waveform. $V_{\mathrm{dc} 1}$ is the voltage of the output capacitor $C_{1}$, and $i_{\mathrm{L}}$ is the current of boost inductor $L$. It shows the load from $144 \Omega$ changed to $72 \Omega$. The response of output voltage and input current was obtained. After the system was put into operation, when the load changed abruptly from $144 \Omega$ to $72 \Omega$, it can be seen from Figure 12a that under the conventional PI double loop control, the output voltage overshoot was large, and reached a new stable state after about $0.15 \mathrm{~s}$ adjustment; after $0.05 \mathrm{~s}$ adjustment, the output current reached a new stable state. It can be seen from Figure $12 \mathrm{~b}$ that under predictive PI control, the output voltage overshoot was relatively small and reached a new stable state after about $0.075 \mathrm{~s}$ adjustment; the output current reached a new stable state after $0.05 \mathrm{~s}$ of adjustment. Through the previous comparison, it can be seen that the system adopted predictive PI control; in the case of load mutation, the overshoot was small, and the dynamic performance was significantly improved.

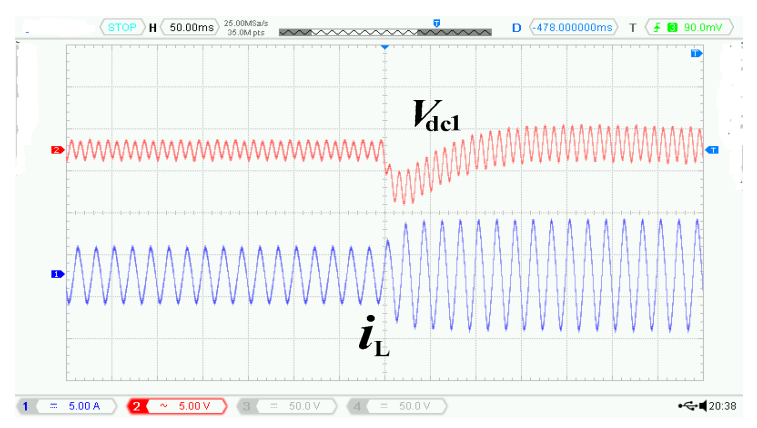

(a)

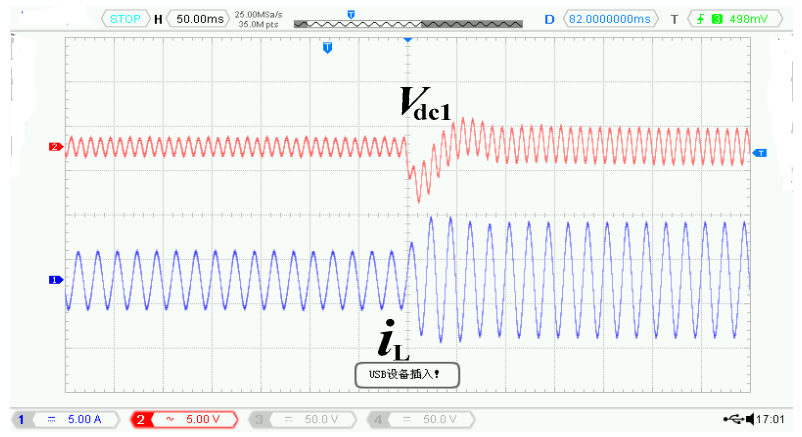

(b)

Figure 12. Output voltage and input current response to load change from $144 \Omega$ to $72 \Omega$ : (a) Traditional double loop PI control; (b) predictive PI control.

Figure 13 is the experimental waveform. $V_{\mathrm{dc} 1}$ is the voltage of the output capacitor $C_{1}$, and $i_{\mathrm{L}}$ is the current of boost inductor $L$. It shows the load from $72 \Omega$ changed to $144 \Omega$. The response of output voltage and input current was obtained. After the system was put into operation, when the load changed abruptly from $72 \Omega$ to $144 \Omega$, it can be seen from Figure 13a that under the conventional PI double loop control, the output voltage overshoot was large, and it reached a new stable state after about $0.15 \mathrm{~s}$ of adjustment; After $0.1 \mathrm{~s}$ adjustment, the output current reached a new stable state. It can be seen from Figure $13 \mathrm{~b}$ that under predictive PI control, the output voltage overshoot was relatively small and reached a new stable state after about $0.075 \mathrm{~s}$ of adjustment; the output current reached a new stable state after $0.05 \mathrm{~s}$ of adjustment. Through the previous comparison, it 
can be seen that the system adopted predictive PI control; in the case of load mutation, the overshoot was small, and the dynamic performance was significantly improved.

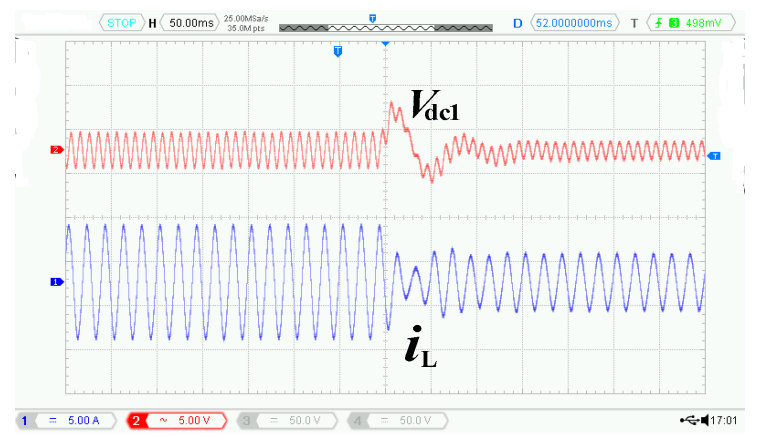

(a)

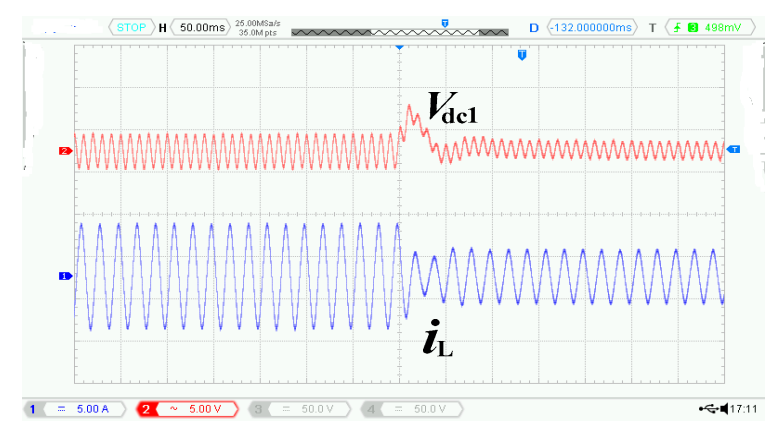

(b)

Figure 13. Output voltage and input current response to load change from $72 \Omega$ to $144 \Omega$ : (a) Traditional double loop PI control; (b) predictive PI control.

\section{Conclusions}

In this paper, according to the characteristics of the double frequency fluctuation of input power of the single-phase AC-DC power converter and the non-minimum phase characteristics of the circuit, a single-phase cascade structure control method based on CHB PFC was proposed. The cascaded multilevel main circuit of the system was modeled by small signal, and the double loop control system of current inner loop and voltage outer loop was established. The results were verified by the experiments, and conclusions were drawn as follows.

(1) The cascaded multilevel structure can effectively improve the system power density of the charger, reduce the voltage drop borne by a single switch, and improve the power factor of the system output.

(2) The carrier phase shift control strategy was adopted to greatly increase the system switching frequency to reduce the burden of each switch and reduce the switching loss.

(3) Predictive PI control was adopted in the voltage loop to effectively improve the dynamic stability of the system.

Author Contributions: G.S. conceived the topology and performed the simulations and experiments; Y.Q. conducted the experiment and analyzed the data. All authors have read and agreed to the published version of the manuscript.

Funding: This research was funded by the Key Research Project of Anhui Education Department (Nos. KJ2021A1139 and KJ2019A0860).

Conflicts of Interest: The authors declare no conflict of interest.

\section{References}

1. IEA. Global-ev-Outlook-2018. Available online: https://webstore.iea.org/global-ev-outlook-2018 (accessed on 2 February 2022).

2. Bortis, D.; Neumayr, D.; Kolar, J.W. $\eta \rho$-Pareto optimization and comparative evaluation of inverter concepts considered for the GOOGLE Little Box Challenge. In Proceedings of the 2016 IEEE 17th Workshop on Control and Modeling for Power Electronics (COMPEL), Trondheim, Norway, 27-30 June 2016; pp. 1-5.

3. Chou, D.; Fernandez, K.; Pilawa-Podgurski, R.C.N. An Interleaved 6-Level GaN Bidirectional Converter for Level II Electric Vehicle Charging. In Proceedings of the 2019 IEEE Applied Power Electronics Conference and Exposition (APEC), Phoenix, AZ, USA, 14-17 June 2021; pp. 594-600.

4. Liu, Z.; Li, B.; Lee, F.C.; Li, Q. High-Efficiency High-Density Critical Mode Rectifier/Inverter for WBG-Device-Based on-Board Charger. IEEE Trans. Ind. Electron. 2017, 64, 9114-9123. [CrossRef]

5. Maheswaria, K.T.; Bharanikumara, R.; Arjunb, V.; Amrishb, R.; Bhuvanesh, M. A comprehensive review on cascaded H-bridge multilevel inverter for medium voltage high power applications. Mater. Today Proc. 2021, 45, 2666-2670. [CrossRef]

6. Hurley, W.G.; Wölfle, W.H. Transformers and Inductors for Power Electronics: Theory, Design and Applications; John Wiley \& Sons: Hoboken, NJ, USA, 2013. 
7. Babu, J.J.; Thirumavalavan, V. Variable Duty Cycle Control with PSO-PI Controller for Power Factor Correction and Fast Regulation. J. Inst. Eng. India Ser. B 2021, 1-9. [CrossRef]

8. Cai, Y.; Xu, J.; Yang, P.; Liu, G. Design of double-line-frequency ripple controller for quasi-single-stage AC/DC converter with audio susceptibility model. IEEE Trans. Ind. Electron. 2019, 66, 9226-9237. [CrossRef]

9. Villarroel, F.A.; Espinoza, J.R.; Pérez, M.A.; Ramírez, R.O.; Baier, C.R.; Sbárbaro, D.; Silva, J.J.; Reyes, M.A. Stable Shortest Horizon FCS-MPC Output Voltage Control in Non-Minimum Phase Boost-Type Converters Based on Input-State Linearization. IEEE Trans. Energy Convers. 2021, 36, 1378-1391. [CrossRef]

10. Su, Y.; Ge, X.; Xie, D.; Wang, K. An Active Disturbance Rejection Control-Based Voltage Control Strategy of Single-Phase Cascaded H-Bridge Rectifiers. IEEE Trans. Ind. Appl. 2020, 56, 5182-5193. [CrossRef]

11. Ming, W.L.; Zhong, Q.C.; Zhang, X. A Single-Phase Four-Switch Rectifier With Significantly Reduced Capacitance. IEEE Trans. Power Electron. 2015, 31, 1618-1632. [CrossRef]

12. Bai, L.; Ren, X.; Hui, Q.; Wu, Y.; Li, K.; Guo, Z.; Zhang, Y. Dynamic response optimization forinterleaved boost PFC converter with improved dual feedforward control. In Proceedings of the 2017 IEEE Energy Conversion Congress \& Exposition, Cincinnati, OH, USA, 1-5 October 2017; pp. 5280-5286.

13. Leung, K.H.; Loo, K.H.; Lai, Y.M. A Family of Ripple Estimation-Cancellation Methods Based on Switched-Resistor Circuits and Their Application in Fast-Response PFC Preregulator. IEEE Trans. Power Electron. 2017, 32, 2608-2621. [CrossRef]

14. Yao, C.; Zhang, Y.; Chen, H. Adaptive Constant Power Control of MHz GaN-Based AC/DC Converters for Low Power Applications. IEEE Trans. Ind. Appl. 2018, 54, 2525-2533. [CrossRef]

15. Mallik, A.; Lu, J.; Khaligh, A. Sliding Mode Control of Single-Phase Interleaved Totem-Pole PFC for Electric Vehicle Onboard Chargers. IEEE Trans. Veh. Technol. 2018, 67, 8100-8109. [CrossRef]

16. Li, S.; Lu, W.; Yan, S.; Zhao, Z. Improving Dynamic Performance of Boost PFC Converter Using Current-Harmonic Feed forward Compensation in Synchronous Reference Frame. IEEE Trans. Ind. Electron. 2020, 67, 4857-4866. [CrossRef]

17. Xiao, D.; Alam, K.S.; Norambuena, M.; Rahman, M.F.; Rodriguez, J. Modified Modulated Model Predictive Control Strategy for a Grid-Connected Converter. IEEE Trans. Ind. Electron. 2021, 68, 575-585. [CrossRef]

18. Kwak, S. Model predictive direct power control with vector preselection technique for highly efficient active rectifiers. IEEE Trans. Ind. Inform. 2015, 11, 44-52. [CrossRef]

19. He, T.; Lu, D.D.-C.; Li, L.; Zhang, J.; Zheng, L.; Zhu, J. Model-Predictive Sliding-Mode Control Three-Phase AC/DC Converters. IEEE Trans. Power Electron. 2018, 33, 8982-8993. [CrossRef]

20. Vazquez, S.; Rodriguez, J.; Rivera, M.; Franquelo, L.G.; Norambuena, M. Model predictive control for power converters and drives: Advances and trends. IEEE Trans. Ind. Electron. 2017, 64, 935-947. [CrossRef]

21. Qi, C.; Chen, X.; Tu, P.; Wang, P. Cell-by-Cell-Based Finite-Control-Set Model Predictive Control for a Single-Phase Cascaded H-Bridge Rectifier. IEEE Trans. Power Electron. 2018, 33, 4857-4866. [CrossRef]

22. Leung, K.H.; Loo, K.H.; Lai, Y.M. Unity-power-factor control based on precise ripple cancellation for fast-response PFC preregulator. IEEE Trans. Power Electron. 2016, 31, 3324-3337. [CrossRef]

23. Zheng, D.; Ren, Z.Y.; Fang, J.A. Stability analysis of multiple time-delayed system. ISA Trans. 2008, 47, 439-447. [CrossRef]

24. Airikka, P. Stability analysis of a predictive PI controller. In Proceedings of the 2013 21st Mediterranean Conference on Control and Automation, Platanias, Greece, 25-28 June 2013; pp. 1380-1385. 